\title{
Editorial - The Torture Journal: A home for all
}

\author{
Pau Pérez-Sales, MD, PhD, Psych*, Editor in Chief
}

Whilst there are positive developments in the field, the failure of President Obama to close Guantanamo Bay after eight years in power exemplifies the challenges that face us: many Guantanamo detainees were originally captured with the acquiescence of democratic governments; both international and American laws were supposedly circumvented by basing Guantanamo outside America and classifying the detainees as terrorists; the authorities developed a programme of "evidence-based" torture under the supervision of clinicians with connections to the American Psychological Association'; and, despite the will of President Obama, legal advisors and Congress have prevented Guantanamo's closure and polls even suggest that a majority of the US population are against its closure. 730 of the detainees have gradually been freed, including 20 prisoners who are to be released before the new President takes office, and these individuals and their families need the care and attention of the rehabilitation sector. Eight have died (allegedly having committed suicide) and ten have been convicted by a military tribunal not recognised by the American justice system. Of the original 779 , only 31 detainees have been deemed too dangerous to be released. They are likely to remain at Guantanamo for the rest of their lives as the authorities are unlikely to want the torture practised on them to come to light. This is a human rights catastrophe that has not only

\footnotetext{
*) SiR[a] Centre, GAC Community Action Group and
} Hospital La Paz, Spain. deeply affected hundreds of lives and helped fuel radicalism, but has fundamentally challenged democracy. Against this heritage, Donald Trump has recently condoned waterboarding ${ }^{\mathrm{ii}}$ and has said "the unthinkable" should be carried when it comes to prisoner interrogation. ${ }^{\text {iii }}$

Our duty here is to also think the unthinkable and try to react to it; our sector remains more crucial today than it ever has and I hope to ensure that the Torture Journal will continue adding value to this work.

The presence and work of the previous Editor in Chief, Lilla Hárdi, lives on in this issue which is largely a reflection of her work. The set of papers entitled 'Incommunicado detention and torture in Spain' was first discussed with Joost den Otter when he was Editor in Chief and has been edited by Lilla Hárdi. The study has been conducted by the Istanbul Protocol Project in the Basque Country Working Group, Benito Morentin, Olatz Barrenetxea, Miguel Angel NavarroLashayas, Pau Pérez-Sales, Angeles Plaza, Oihana Barrios Salinas, Gabriela Lopez-Neyra and Maitane Arnoso Martínez. The study provides an in-depth analysis of how contemporary torture operates in European societies, with Spain and the Basque country as a case

i See Torture Journal Vol.15, No.1 2005 pp66-70; Vol.16, No.1 2006 pp65-66.

ii Donald Trump on waterboarding: "Torture works". Washington Post. 17 February 2016. iii Trump Amps Up His Call For Torture: 'We're Going To Have To Do Things That Are Unthinkable'. Huffington Post. 30 June 2016 
study. Ill-treatment and torture based on physical pain have been left behind. Patterns of coercion on human freedom have advanced to more complex and efficient ways of breaking the will of the individual. Contemporary torture emphasises attacks on the conscious mind to target the self and identity in a process that, according to the study, needs no more than three to five days to achieve physical and psychological breakdown. The study, conducted over a four-year period by a team of 25 forensic psychiatrists, psychologists and physicians, presents a particular way of using the Istanbul Protocol (IP) for advanced forensic research. The authors highlight some shortcomings of the IP that they deem important.

The article 'Enhancing empathy among humanitarian workers through Project MIRACLE: Development and initial validation of the Helpful Responses to Refugees Questionnaire' by Miriam Potocky and Kristen Guskovict is an unusual and extremely useful work. It proposes a scale to measure empathy in working with victims. The effectiveness of counselling and psychotherapy as part of the rehabilitation of victims of torture depends less on a closed set of tools or methods than on what contemporary psychotherapy calls the non-specific elements of therapeutic work, and specially interviewing skills, empathy and compassion. Furthermore, empathy must permeate the work of all professionals in the rehabilitation team, including non-therapists. The authors propose a brief and innovative scale that allows for pre and post intervention measures, assessing the impact of training workshops on counselling, or even selecting candidates for a team.

On a different but concurrent side of the IP debate, in 'A comparative study of the use of the Istanbul Protocol amongst civil society organizations in low-income countries', Kelly et al. question the usefulness of the IP due to its excessive complexity for the average human right's worker. Their argument, based on interviews in three countries, is that in most places were torture is widespread, access to justice is simply impossible and workers face considerable risks when working with individual cases. Frontline workers would demand a simpler and straightforward model.

Experts in the field challenge these findings in the Debate section of the journal. They question who the interviewees were, what their training and experience was, and stress that the IP can be adapted for different purposes and this is part of the training process. It is not acceptable, says Dr Özkalipci, to have two standards of quality for high and low income countries, but it is mandatory to have a high standard and adapt the tool accordingly.

As these debates show, the Torture Journal is the place where our community of scientists, practitioners and survivors can debate with science as a key point of reference, and can hopefully assist in informing public opinion and decision-makers. It must be a home for all.

I would finally like to pay tribute to and thank all the past Editorial Advisory Board members and particularly the previous Editors in Chief, Henri Marcussen, Ole Vedel Rasmussen, Joost den Otter and Lilla Hárdi. They have made the journal the main scientific reference in medical and psychological research in the field of torture.

With respect to the future, the members of the editorial team and the Editorial Advisory Board look forward to sharing some of the key ideas for the next steps in the history of the journal in the next issue. We can also look forward to the IRCT's Scientific Symposium in Mexico in December with its more than 200 presentations. This is a unique opportunity to get a global picture of the field at this time, as well as reviewing past achievements and ways forward. Lastly and importantly, we wish to express again that we welcome and look forward to your contributions; the Torture Journal must strive to be a home for all. 